\title{
Josef-Maria Jauch in Memoriam
}

\section{P.-O. Löwdin, Uppsala G. J. Béné, Geneva}

With the sudden and unexpected death of Josef-Maria Jauch on $30 \mathrm{Au}$ gust 1974 , the physics community lost one of its outstanding leaders, and mankind one of its finest and most remarkable human beings. He was born on 20 September 1914, in Lucerne, Switzerland, and, after studies at ETH, Zürich, and as exchange fellow at the University of Minnesota, he became in 1940 research assistant to Wolfgang Pauli at ETH. Because of the war, Pauli left almost immediately for the United States, but Jauch stayed in Zürich until July 1942, at which time he joined Pauli in Princeton. He worked with him on the strong-coupling theory of the nucleons and particularly on their magnetic moments first by the $\lambda$-limiting process and then by the method of field quantization. This was a period of fruitless attempts all over the world to understand the elementary particles and, in both cases, they obtained negative results.

At the end of the war in 1945, Jauch went to the Bell Telephone Laboratory at Murray Hill, N.J., for a year to do some "real physics", but he missed the students. In 1946, he accepted a position as professor of theoretical physics at the University of lowa, where he was to stay until 1959, working with many students on quantum electrodynamics and the nature of the elementary particles. He returned to Europe in 1959 as a liaison officer at the London branch of the Office of Naval Research and, in a series of excellent reports, he analized the status of physics in most of the West-European countries. The London year was a preparation for taking over the chair of theoretical physics at the University of Geneva, which he had accepted in 1959.

In Geneva, Jauch reorganized particularly the department of theoretical physics, and his physics seminars were soon to be world-famous.

He continued his studies of scattering theory, and he became deeply interested in the fundamental concepts of physics: the measurement process, the symmetry properties, the casuality problem, the phenomenon of irreversibility, the gauge invariance etc.., and many of his 85 research papers deal with the axioms of physics. He introduced a mathematical ri- gour to theoretical physics which had seldom been seen before.

His book 'The Theory of Photons and Electrons' (1955) with F. Rohrlich has been the introduction to the renormalization procedures for many generations of students in theoretical physics. His 'Foundations of Quantum Mechanics' (1968) as well as "Are Quanta Real? A Galilean Dialogue" (1973) are subject for intense studies at many physics seminars all over the world

Jauch had also a deep interest in the humanistic sides of life: music, art, philosophy, and the problem of scientific creativity, and he made in 1964 a penetrating study of Galilei and his fate in connection with the 400th anniversary of Galilei's birth.

For Jauch's sixtieth birthday on 20 September 1974, his many collaborators and friends had prepared a dedicatory volume 'Physical Reality and Mathematical Description', edited by Charles P. Enz and Jagdish Mehra, in which the lasting impact of JosefMaria Jauch on the present and future development of theoretical physics is clearly documented. pean Physical Society has lost one of its founding members, the University of Geneva one of its most internationally famous and distinguished faculty members, and the scientific community one of its great pioneers.

P.-O.L.

It was on 5 January 1966 that Jauch was invited by Bernardini, then President of the Italian Physical Society, to take part in a meeting, scheduled on 16-17 April in Pisa on "General aims and problems concerning European Physicists". He was asked also to cooperate in the preparation of the agenda for this meeting.

In his reply his enthusiasm was already evident and he set down some of the questions about which he felt so strongly (letter of 14 January 1966). It is worth recalling here the essence of this document which is every bit as valid today.

"I shall appreciate very much sharing some of my concerns about the recent trends in theoretical research with others who have also thought
With the death of Jauch, the Euro-

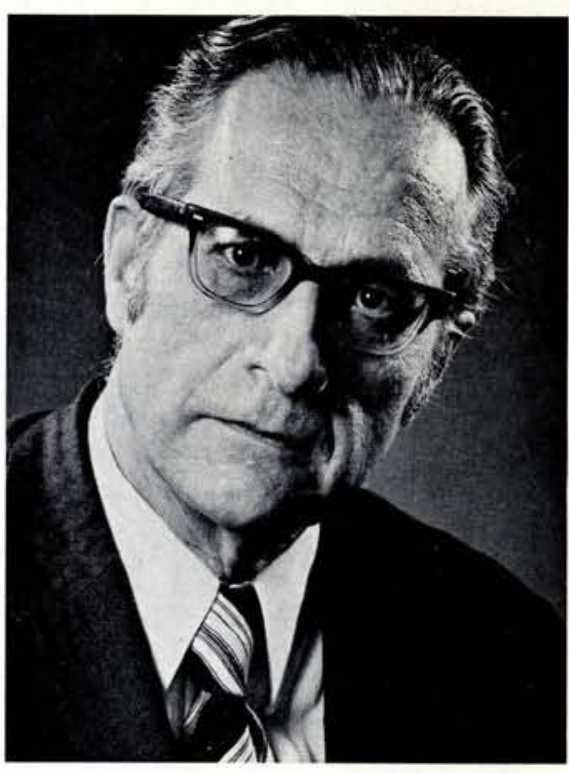

Joset-Maria Jauch

about these problems. It seems to me that we have an overproduction on mediocre papers and one should find ways and means to raise the standards of the papers which are being published. It would perhaps be useful to analyse the reasons for this state of affairs and to try to get at the causes of the trouble.

Another problem which has worried me for some time is the insufficient contact between mathematicians and theoretical physicists. The latter often continue to use methods which from the modern mathematical point of view are almost primitive. The mathematicians, on the other hand, could receive much interesting motivations from the physicists.

During a recent meeting of the editorial Committee of the Helvetica Physica Acta (HPA), of which I am the president, we discussed still another problem, the deploring lack of communication and comprehension between different branches of physics. And yet we have before our eyes the fruitful impact of field-theoretic methods in solid state physics, Lie algebras or superconductivity in high energy physics and similar cross-fertilisations which to me are some of the most exciting developments of recent years. We have, therefore, decided to make an experiment with some commissioned review articles to be published in the HPA in the future.

We hope in this way to contribute a little towards a better mutual understanding among the various branches of specialization.

Finally, I wish to mention the much broader and perhaps most important complex of problems whether physics is to become a job for technicians, highly trained to be sure and skilful, but of limited horizon and integrated into efficiently organized teams. Or is there room for some of the excite- 
ment of the discovery and the birth of new ideas? Is physics part of our western culture? Does it make sense to see and reveal beauty in the laws of nature or is that hopelessly oldfashioned?

When Galileo discovered the moons of Jupiter, people wrote poems about this event. Thus was the imagination of the whole man enthralled by a scientific discovery in the 17th century. How far we are today from such an attitude!

These are some of the questions over which I muse sometimes. Do you think that some of them might be discussed at such a meeting as you are planning?".

The contribution of Jauch to the meeting at Pisa was particularly dynamic as Bernardini recalls briefly in his letter of 27 May 1966.

"I well remember your precious contribution given to the Pisa meeting with your speech, as well as your interest about the possibility of establishing in the future the European Physical Society".

In the same letter Jauch was asked to become a member of the "Steering Committee for planning the actions to be taken to promote the institution of such a society", an invitation which he accepted with enthusiasm.
The first meeting of the Steering Committee at CERN on 25 November 1966, other meetings during 1967 and 1968 and the many working parties which over this period met together in his own office at the Ecole de Physique, gave Jauch the opportunity through the University of Geneva, of giving maximum support to these activities.

This support was acknowledged by the decision taken by the Steering Committee before its dissolution to hold the ceremony of inauguration in the aula of the University of Geneva on 26 September 1968 under the presidency of the Rector M. Denis Van Berchem.

Jauch was to become a particularly active member of the first executive of the European Physical Society, in office from September 1968 to April 1969 after which he prefered to step down to encourage a regular progressive renewal of the directing bodies. This renewing seemed to him an indispensable condition for the vitality and development of the society.

We lose in the person of Professor Jauch a scientist who was profoundly European, one who believed in human values and the fraternity of science as a whole.

G.J.B.

\section{Society News}

\section{Member Societies}

\section{Ampere Group}

The new President is E.R. Andrew, Nottingham.

\section{Austrian Physical Society}

The new President is F. Cap, Innsbruck.

\section{Finnish Physical Society}

The new Secretary is I. Suortti, Helsinki.

\section{Italian Physical Society}

The new Secretary is G.A. Wolzak.

The Netherlands' Physical Society

The new President is A.M. Hoogenboom, Utrecht.

Physical Section, Union of Czechoslovak Mathematicians and Physicists

The new President is J. Pastrnak, Prague.

\section{New Books:}

\section{The Quantum Principle}

by JAGDISH MEHRA

This study deals with the development of, and the current discussion about, the interpretation of quantum mechanics. Dfl. 44,- / US $\$ 16.50$ ISBN 90-277-0469-4

\section{Einstein, Hilbert, and the Theory of Gravitation}

\section{by JAGDISH MEHRA}

A remarkable essay about two intellectual giants of the twentieth century which throws new light on their scientific temperaments and personalities.

Dfl. 27,50 / US $\$ 10.00$ ISBN 90-277-0440-6

\section{Ludwig Boltzmann: Theoretical Physics and Philosophical Problems. Selected Writings}

(Translated from the German, edited by B. McGuinness)

Vienna Circle Collection Volume 5

Cloth approx. Dfl. 85,- / US $\$ 32.50$ ISBN 90-277-0249-7

Paper approx. Dfl. 43,- / US \$16.50 ISBN 90-277-0250-0

Catalogues and leaflets will be sent on request.

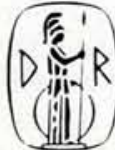

\section{Reidel Publishing Company}

Dordrecht - Holland / Boston - U.S.A.

\section{Divisions}

\section{Atomic Physics}

The new Secretary is G. zu Putlitz, Heidelberg.

\section{Electronic and}

\section{Atomic Collisions Section}

The new Secretary is F.J. De Heer, Amsterdam.

\section{Nuclear Physics}

The new Secretary is W.D. Hamilton, Brighton.

Editor: Lorette Etlenne-Amberg.

Editorial Advisory Panel:

G.J. Béné, B. Glovanninl,

G. Harbeke, E.N. Shaw, J.J. Went.

All correspondence to:

Editor, EUROPHYSICS NEWS,

European Physical Soclety,

P.o. Box 39,

CH - 1213 Petti-Lancy 2

Phone: Geneva 931132

Switzerland.

Published by the European Physical Soclety

Printed by: Ed. Cherix et Filanosa S.A. $\mathrm{CH}-1260$ Nyon, Switzerland. 